\title{
getsis
}

\section{Journal of Management Sciences \\ Training and Development Methods affecting Professionalism and Empowerment of Banking Sector Employees}

\section{Affiliation:}

Adnan Faridi

Public Administration Department, University of Karachi, Pakistan.

E-mail: farid80@gmail.com

Akhtar Baloch

Public Administration Department, University of Karachi, Pakistan.

Email: abaloch@uok.edu.pk

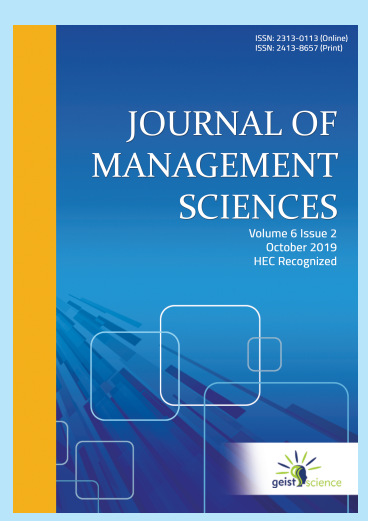

\section{Manuscript Information}

Submission Date: August 23, 2019

Acceptance Date: October 21, 2019

\section{Citation in APA Style:}

Faridi, A., \& Baloch, A. (2019). Training and Development Methods affecting Professionalism and Empowerment of Banking Sector Employees, Journal of Management Sciences, 6(2), 75-92.

DOI: https://doi.org/10.20547/jms.2014.1906206 


\title{
Training and Development Methods affecting Professionalism and Empowerment of Banking Sector Employees
}

\author{
Adnan Faridi * $\quad$ Akhtar Baloch ${ }^{\dagger}$
}

\begin{abstract}
This study investigates the role of training and development methods in improving the empowerment and professionalism among the banking industry of Pakistan. It also determines the comparison between the modern and traditional methods in private and public banks. Using purposive and convenient sampling techniques, total 380 responses were gathered from professionals working in the banking sector of Pakistan. The results showed in that private banks, professionalism and empowerment significantly get improved under modern methods in contrast with traditional methods at public banks. Moreover, findings also revealed that professionalism and empowerment are positively affected by the modern methods of training whereas there is non-significant impact of traditional training on empowerment and professionalism. Permanent employees showed greater professionalism and empowerment as compared to contractual employees. The study theorizes that modern methods of training leads to empowerment, which further enhances the professionalism among banking industry of Pakistan.
\end{abstract}

Keywords: Contractual employees, empowerment, modern methods, permanent employees, traditional methods.

\section{Introduction}

"Training and development (T\&D) is important for survival of every organization", says (Chughtai \& Nadeem, 2016; Jaffery \& Farooq, 2015). Intense competition often leads to several types of challenges for the businesses. In order to remain competitive, the organizations opts for training and development. Shafiq and Hamza (2017) argued that, "the major assets in the organization is the employee, they have a role to play towards an organizational success. The success of the organizations cannot be underestimated by the organizations" (p. 42). Thus, it is important for the organizations to train and development of employees. According to Kulkarni (2013), "training is the nerve that suffices the need of fluent and smooth functioning of work which helps in enhancing the quality of work life of employees and organizational development too" (p. 136). According to Kulkarni (2013); Ali, Bashir, and Mehreen (2019), "development is a process that leads to qualitative as well as quantitative advancements in the organization, especially at the managerial level, it is less considered with physical skills and is more concerned with knowledge, values, attitudes and behaviour in addition to specific skills". Therefore, it

*Public Administration Department, University of Karachi, Pakistan. E-mail: farid80@gmail.com

$\dagger$ Public Administration Department, University of Karachi, Pakistan. Email: abaloch@uok.edu.pk 
could be concluded that training has higher specificity element by focusing on particular objectives and areas to improve whereas development is a continuous process to polish existing knowledge, skills and abilities (KSA). In other words, a new employee requires training so that job related required skills and abilities could be developed while development is a process to upgrade existing set of knowledge and capabilities.

Government institutions have a role in improving the quality and performance, therefore, it cannot be separated which is only the responsibility of the individual organizations. Production and services are the backbone of every country (Imran, 2018). Banking sector is one of the service sectors that has gain steady growth in recent times within Pakistan. A plethora of research showed that training and development (T\&D) is one of the significant HR practices widely used in the organisational setting to ensure optimal use of resources (Faizan \& Zehra, 2016; Faridi, Baloch, \& Wajidi, 2017). The core agenda for the use and implementation of T\&D in professional setting is to ensure a set of required knowledge, skills, capabilities and abilities in relation to assigned tasks and responsibilities are attained. The study of Zehra (2016) defined T\&D as a barometer for measuring the performance of employees as well as of banks. However, T\&D practices along with all other HR practices are more visible in the developed countries in comparison to emerging ones (Faridi et al., 2017). Rehman (2012) argued that, "the major difference between the first and third world economies is the effectiveness and usages of the human resource practices" (p. 02). Insufficient knowledge related to task requirements develop negative psychology, which leads to less, or untrained employees have higher chances of losing job opportunities (Batool \& Batool, 2012). This alternatively increases the probability of resource wastage such as new process of hiring. Studies have confirmed that employees (trained ones) last longer in the organizations while inadequately trained employees quit jobs (Caldwell, 2003; Hales, 2005). Thus, the psychological and intellectual capital develops for the organization in a long run due to appropriate training and development methods. There is a positive impact of training on the growth and success of the organization as the quality of work improves through the employees' recognition of responsibilities and duties. "Training implies constructive development in such organizational motives for optimum enhancement of quality of work life of the employees" (Kulkarni, 2013). Interestingly, the different methods of training and development are constructive in improving the employees working efficiency, professional attitude, engagement and loyalty at work and uplifting moral (Faridi et al., 2017; Faridi \& Baloch, 2018).

Gusdorf (2009) stated that the business practices, functionality and operations have changed to a larger extent due to the intense competition, development and advancement in latest technologies, and emergence of new trends in the market. However, it is equally important for the employees to learn and strengthen their skills and expertise in the supportive environment (Faridi et al., 2017). On the other hand, employees' performance is frequently affected by performance appraisal politics too (Imran, 2018), which makes an interesting argument whether the professionalism of the employees is reduced due to it or not. Noe and Peacock (2008) argued that it is essential for the organizations to develop a learning atmosphere and hire professional trainers for different types of development of skills and attributes required to perform tasks. Micro training significantly affects the sustainability of the workers (Haque \& Oino, 2019). Gender diversification is 
another area that improves the organizational performance (Faizan, Haque, Cockrill, \& Aston, 2019), but how the empowerment works in the higher gender diversification is not conclusive from the literature.

Furthermore, the organization shall also consider the latest types of techniques and technologies that enhances employees' creativity, professionalism and empowerment so that there is more commitment towards assigned tasks and responsibilities (Faridi et al., 2017; Noe \& Peacock, 2008). Within the professional business environment, it is a common concept that improvement of employees of KSA leads to improved performance of the sector (Zehra \& Faizan, 2017). However, it equally requires proper strategic planning to educate the resources in the right manner. Hence, T\&D programs are effective in promoting the highest level of creativity and innovation among professionals through supportive environment, professional trainers and latest techniques.

The recent study of Mukwakungu, Mankazana, and Mbohwa (2018) attempted to explain the concept of empowerment in the context of organization, by stating that it is a phenomenon that generally indicate an employee within the organization have enthusiasm and energy through being psychologically active to take initiation and work his/her way to ensure the organizational gaols are attained through his/her made choices and plans. It is an attribute that gives the liberty to the workers in the organizational setting to use their own creative abilities and set of skills to ensure the quality of their work along with the improvement organizational performance (Mukwakungu et al., 2018). The idea of empowering employee is highly effective in the reduction of customer complaints and reduction of cost for the organization. In simplistic terms, it is improving the psychological being of the employees by giving them creative liberty. It helps the organization in fostering teamwork and improving the reputation of the organization.

The latest techniques of training and development has been in demand due to extensive competition (Faridi et al., 2017). The training procedures have changed due to globalization (Faridi \& Baloch, 2018). Thus, nowadays, banking sector has also changed it strategy by adopting new methods and policies, especially in the developed economies (Bloom \& Van Reenen, 2007; Noe \& Peacock, 2008). Nowadays, service sectors including banking sector are promoting online training programs to educate their workforces. The traditional means and methods of training have become outdated in many organizations (Noe \& Peacock, 2008). Those organizations that are still operating with traditional methods of training are lagging behind in competition with the organizations using modern methods of training. There is a transformation in the management's style of operation, structure and approaches. The traditional mode of HR practices has largely remained ineffective in dealing with new requirements of constantly changing business environment (Zehra, 2016).

The ability of T\&D includes transformation of a person from selective to be more adaptive so that he/she could work in different organizational settings (Stone, Stone-Romero, \& Lukaszewski, 2006). Bloom and Van Reenen (2007) argued that the internal and external environment do not affect the performance of the employee if employee has the ability to mould according to the requirement and situations. However, the flexibility in personal stance is more required under new techniques while traditional methods are largely structured. To larger extent, still in the emerging economies, traditional meth- 
ods of training such as lectures, using desk filling, seminars, lectures and workshops are more common (Zehra, 2016). In other words, the training process is carried out in traditional methods. However, there is a shift in paradigm, especially in the private sector, the computer-based-training (CBT) and online methods are evident in the emerging economies (Faridi \& Baloch, 2018; Faizan \& Zehra, 2016).

Levy, Wubbels, Den Brok, and Brekelmans (2003) argued that modern methods of training are more effective in comparison to traditional methods because it offers more flexibility, re-usability of content, timelines, knowledge acquisition and foster learning autonomy. Traditional methods have higher specificity in time window and pre-set structure that limits the learning capabilities while modern methods offer higher flexibility so that there is less pressure and individuals could acquire knowledge at their own generic pace (Levy et al., 2003; Shafiq \& Hamza, 2017). Similarly, in traditional method, there is technical limitation because individuals could struggle to achieve all essential components of session if misses out while modern methods offer the re-use of content, especially in online methods. Furthermore, traditional methods set-up time frame while following rigid formal patterns whereas modern method provides upgraded material with latest information. Nevertheless, Zehra (2016) argued that it is not easiest of tasks for the organizations to implement latest technologies and methods for the employees, especially in the public sector having large number of aged employees. On the other hand, in developed economies, the information technology is more advanced and continued to evolve while also implemented in the organization at a faster rate than in the emerging economies (Faizan \& Zehra, 2016).

The interaction among employees and departments have rapidly enhanced due to the latest technologies (Stone et al., 2006). The traditional methods of training and development also had a limitation of face-to-face interaction while following rigid structural pattern whereas the modern methods have overcome this limitation. Employees' professionalism and higher level of empowerment is evident due to incorporation of information technology in the HR practices. Furthermore, the modern methods are cost effective as they save time, money and other resources for the organizations (Faizan \& Zehra, 2016). Information technology and latest methods does not only improve HR functionality but also enhances the quality of work, professionalism, employee engagement, empowerment and personal and professional KSA (Haque \& Oino, 2019; Faridi et al., 2017). Based on the identified gap in the literature, hypothesis 1 is proposed below:

$H_{1 a}:$ Modern TED methods are more effective in improving the empowerment of permanent employees.

$H_{1 b}$ : Traditional TED methods are more effective in improving the empowerment of permanent employees.

$H_{1 c}:$ Modern TED methods are more effective in improving the empowerment of contractual employees.

$H_{1 d}$ : Traditional TED methods are more effective in improving the empowerment of contrac- 
tual employees.

Theoretical foundation for employees' creative behaviour is provided through the Social Exchange Theory (SET) (Nawaz, Hassan, Hassan, Shaukat, \& Asadullah, 2014). In recent times, the SET in relation to employee engagement is frequently used as well as accepted theory. As per SET, training and empowerment given to employee leads to develop a positive psychology to repay the organization by demonstrating engaged behaviour (Andrew \& Sofian, 2012). The behavioural engagement of employees drives them to perform their duties with more sense of responsibility, reflecting professionalism and empowerment that promote creativity and innovation at workplace. Furthermore, the engaged employees work as a role model for the other employees whereas disengaged employees cost organization through lower productivity, turnover and higher absenteeism (Andrew \& Sofian, 2012). As per SET theory employees demonstrate their best when organization take care of them. It reflects the social exchange relationship as the employees repay for good care with improved organizational performance (Cropanzano \& Mitchell, 2005). Similarly, trained and empowered employees are more dedicated towards the jobs through using their physical, cognitive and emotional resources. Employees with higher empowerment use their creative skills more efficiently and effectively in the customer services (Nawaz et al., 2014).

The literature has confirmed that employees are more productive when they are trained (McClelland, 2002; McNamara, 2008). Still, the use of modern versus traditional methods in the public and private banking sector is under researched. Furthermore, there are still limited traces of effective modes of training and development methods from banking sector of emerging economy (Faridi \& Baloch, 2018; Zehra, 2016). The findings of Baldoni (2005) indicated that training and development methods are pivotal for both; employees and organizations as it enhances the organizational performance while promoting the sense of empowerment and professionalism. It could be argued that development of professionalism is a result of training method, but which method is more adequate is still debatable. Pre-planning is another aspect of professionalism that helps in the reduction of risk for the organization (Urbański, Haque, \& Oino, 2019). Nevertheless, considering the type of employees such as contractual and permanent employees in distinctive sector, there are no conclusive evidences. Since there is no conclusive evidence from the existing literature about contractual and permanent employees' perspective, which makes it more intriguing to find the variable of interest. Therefore, below is the hypothesis 2 :

$H_{2 a}$ : Modern TED methods are more effective in the development of professionalism of permanent employees.

$H_{2 b}$ : Traditional TED methods are more effective in the development of professionalism of permanent employees.

$H_{2 c}$ : Modern TED methods are more effective in the development of professionalism of contractual employees.

$H_{2 d}$ : Traditional TED methods are more effective in the development of professionalism of 
contractual employees.

"There are several types of challenges faced by management related to work, worker and workplace" (Haque \& Oino, 2019). In order to meet such challenges, training and development is most widely used by the organizations. Notable work in the area of organizational behaviour have found the importance of T\&D in the development of professional attitude and behaviour (Faizan \& Zehra, 2016; Noe \& Peacock, 2008; Stone et al., 2006). However, the previous empirical studies have been largely limited to the either developed economies, focusing on single case whereas this research considers comparative lens to examine the distinctive type of training methods affecting contractual and permanent employees working within the private and public banks of Pakistan. Thus, this study takes more comprehensive step to consider all the distinctive features within one construct. The study contributes to enhance the existing literature through providing evidence from comparative lens in multidimensional manner. Especially, considering how the specific type of training could improve the professionalism by empowering the employees is yet under researched.

"Professionalism serves as a tool of social control that informally approves, constrains, or prohibits work behaviours". Nowadays, higher emphasis is on the needs for professionalism at organisational setting (Ferguson, 2014; Rowland, 2016). It is associated closely with the organizational values like business ethics, commitment, and integrity (Aho, 2013; E. Brown, 2013). It tends to improve the job outcomes and professional identification (Dinger, Thatcher, Treadway, Stepina, \& Breland, 2015). On the other hand, recent study explained it by stating that professionalism reflects the specialized knowledge, competency, and integrity attribute of the individual at the organizational setting (Faridi $\&$ Baloch, 2018). It enables the person to execute the assigned core activities with the professional attitude, conduct, aim and specific qualities. There is statistically significant relationship between the employee engagement and modern methods of training and development. Same study also indicated that professionalism of banking sector employees enhances under modern methods of training and development. There are previous studies that have indirectly considered the empowerment improves the professionalism, yet those studies (such as, Zehra and Faizan (2017); Faridi et al. (2017)) have not investigated the research phenomenon in direct mode. However, there is no conclusive evidence from comparative perspective to assess the relationship between research variables under public and private banks having contractual and permanent employees.

$H_{3 a}$ : Under modern TED methods, empowerment enhances the professionalism of the permanent employees.

$H_{3 b}:$ Under traditional TED methods, empowerment enhances the professionalism of the permanent employees.

$H_{3 c}$ : Under modern TED methods, empowerment enhances the professionalism of the contractual employees.

$H_{3 d}$ : Under traditional TED methods, empowerment enhances the professionalism of the con- 
tractual employees.

\section{Rationale of the Study}

Previous empirical studies have largely commenced in developed economies while there are traces of few studies from emerging economies, but they have not used the Social Exchange (SET) Theory to investigate both; professionalism and empowerment in relation to type of training methods whereas present study intakes a new dimension to investigate the research variables through SET theory. Moreover, this study also provides the strategic managerial implications to improve the organizational efficiency through enhanced professionalism and empowerment aspect. It also enables the practitioners and academics to enhance the body of understanding about the role of T\&D in creating psychological capital for the banking sector.

This study has an objective to explore the role of distinctive types of training and development methods in relation to professionalism and empowerment of contractual and permanent employees working in the public and private banks of Pakistan.

\section{Conceptual Model}

The conceptual model of this study is based on the future directions given of earlier researchers and identified gap in the literature at hand. Hence, in this model, the traditional and modern methods of training affect the employee empowerment and professionalism while the impact of empowerment on the professionalism of the contractual and permanent employees working in the banking sector are considered as variables of interest.

Figure 1

Conceptual Model

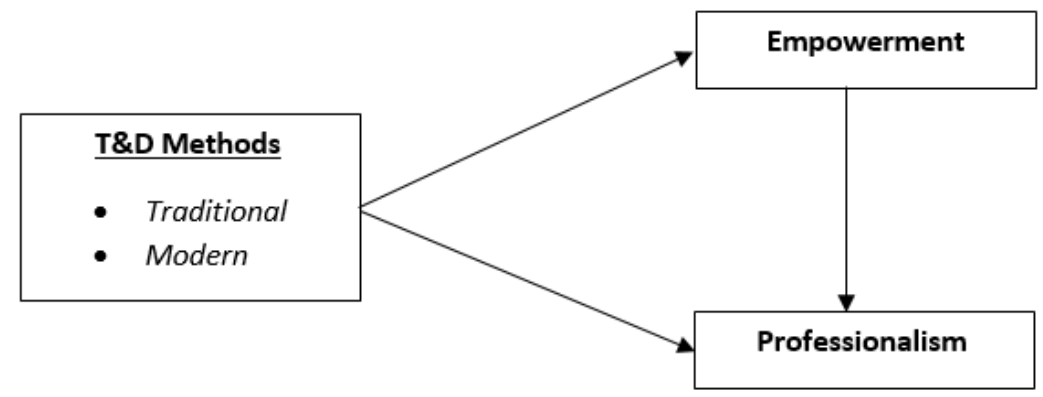




\section{Method}

\section{Research Design}

This study has cross-sectional comparative research as the study is completed within one year while participants have only participated once in a given time interval (Haque \& Oino, 2019; Sekaran \& Bougie, 2016). Inclusion criteria was based on acquiring participation from contractual and permanent employees working at operations, administration and managerial level with graduation as formal education, while all those who were on internship or working as lower clerical staff were excluded. As part of the research, only those private banks are included that uses modern methods of training while public banks using traditional methods of training are included.

\section{Sample Size and Sampling Technique}

Within the scientific research, "margin of error" of \pm 3 is allowed only if there is a control over confidence level and sample size (LeBlanc, 2004). To greater degree, the parameter of population (P) affecting the value of prior judgement value $\left(\hat{p}^{\prime}\right)$ could not be controlled. Thus, M.E Margin of Error formula is effective to attain probable estimation of the population to draw sample size (M.E $\left.=\frac{z \sqrt{\hat{p}(1-\hat{p})}}{n}\right)($ Rumsey, 2002; Jamal, 2011). In social science research, up to \pm 4 could be used (LeBlanc, 2004). This is a social science research using scientific approach therefore margin of error is \pm 4 , which means 0.04 for measuring the sample size with $\mathrm{z}=1.96$ for $95 \%$ confidence interval, $\hat{p}=$ prior judgement of the correct value of $p$ is estimated .2 (i.e. $20 \%$ ). Thus, by using this formula, minimum sample required is 378 , so we ensured we attain more responses than the derived value. The sample size for the present study is 380 respondents, where 190 from Public banks and remaining 190 from the private banks.

Using the strategy of Haque and Oino (2019), the purposive sampling technique is used to ensure whether there is fair and equal representation of the sample size. The respondents were approached through using convenient and purposive sampling technique. Purposive sampling is effective when the focus is on the fair representation of sub-groups of the population (Kot, Haque, \& Kozlovski, 2019). Furthermore, Louangrath (2013) argued that in the social science studies, purposive sampling is frequently employed when the major focus is on the investigation of particular features or set of properties. It was explicitly acknowledged that purposive sampling and convenience sampling are not ideal for the statistical analysis to gain significant result because it "it can per se be prone to bias and as such, compromise the research validity" (Wijnhoven, Ehrenhard, \& Kuhn, 2015). "However, the accuracy of the application of this data collection technique in inferential statistics has been shown tolerable subject to proper safeguards against bias" (De Munnik, Dupuis, \& Illing, 2009; Wijnhoven et al., 2015). Since random sampling required sampling frame, which was not available for this study and probability sampling proved costly because of the "limited access to informants, high non-response rates or other factors complicating randomisation" (Wijnhoven et al., 2015). Thus, for minimizing biases, the stratification between public and private and contractual and permanent 
employees were fairly and equally represented as all major groups. The combination of different sampling techniques is to avoid the over reliance on one method, which limits the ability to reach target audience (Faizan et al., 2019). Total 28 banks participated in this study out of 72 approached banks, reflecting $38.8 \%$ response rate in terms of organizations.

\section{Research Instrument and Measurement Scale}

Training is measured through six item scale of Boshoff and Allen (2000). Moreover, Hayes (1994) scale is used to measure the empowerment with five items. Faridi and Baloch (2018) scale for measuring professionalism with 4 items have been used in this study. All the included items were measured on 5-points Likert scale ( $1=$ strongly disagree, $2=$ disagree, $3=$ neutral, $4=$ agree, and $5=$ strongly agree). The adoption of pre-used scales to measure the items reflect test-retest reliability, discriminant and convergent validity (K. W. Brown \& Ryan, 2003).

\section{Data Collection Procedure}

Firstly, a formal consent was taken from the HR department of the targeted banks. The letter included the purpose of the research, time and duration of research, voluntary participation, confidentiality and anonymity of the participants. After attaining formal consent, personal visits were made to banks and manually circulated the survey questionnaire based on the convenience of the respondents. The brief was given to the participants covering all aspects such as confidentiality, purpose of study, no monetary reward and so on. There was no restriction of time required to completion of questionnaire. The time range was between 10 to 15 minutes while on average it took 12 minutes and 32 seconds. It was ensured that there is equal number of respondents from both; public and private banks with equal ratio of contractual and permanent employees.

\section{Results}

\section{Descriptive Statistics}

The descriptive statistic revealed that banking sector employees comprise of Private banks $(n=190)$ and public banks $(n=190)$, which has majority of males $(62 \%)$ age ranging between $32-39(47 \%)$ with bachelor's degree $(36 \%)$ and 8-10 years' experience of working in the banking sector (31\%).

\section{Measurement Model}

The reliability and validity of the measurement model is assessed in this section. As part of model validation, Cronbach's alpha $(\alpha)$, composite reliability (CR), Average Variance 
Extracted (AVE) are included to measure the reliability while discriminant validity is assessed through Fornell and Larcker Criterion by in both (public and private) banking sectors. "Considering Cronbach's alpha and compositive reality, the value of equal or greater than 0.7 reflect acceptable value while AVE should be equal or above 0.50 " (Hair Jr, Hult, Ringle, \& Sarstedt, 2016; Imran, 2018).

The above table confirmed that Cronbach's alpha $(\alpha)$ in private and public banks are greater than the threshold value (0.70) for all three items on the scale, reflecting that there is acceptable internal consistency (Empowerment (PVT) $\rightarrow 0.89>0.70$; (PUB) 0.77 $>0.70$; Professionalism $(\mathrm{PVT}) \rightarrow 0.82>0.70$; $\mathrm{PUB}) 0.78 \geq 0.70$; Training Methods $(\mathrm{PVT}) \rightarrow$ $0.93>0.70 ; 0.72>0.70$; Table 1$)$. In addition to that, composite reliability (CR) is another criterion considered in this study and results confirmed that the obtained values are greater than benchmark (0.7), reflecting composite reliability is acceptable (Empowerment $(\mathrm{PVT}) \rightarrow 0.87>0.70$; $($ PUB) $0.72>0.70$; Professionalism $(\mathrm{PVT}) \rightarrow 0.77>0.70$; (PUB) 0.71 $>0.70$; Training Methods (PVT) $\rightarrow 0.93>0.70 ; 0.70 \geq 0.70$; Table 1). Lastly, AVE in private and public banks are greater than 0.5 thus, measurement model is valid (Empowerment $($ PVT) $\rightarrow 0.56>0.5$; (PUB) $0.54>0.5$; Professionalism $($ PVT) $\rightarrow 0.52>0.5$; (PUB) $51>0.5$; Training Methods (PVT) $\rightarrow 0.64>0.5$; (PUB) $0.58>0.5$; Table 1). The obtained values of $\alpha, \mathrm{CR}$ and AVE are acceptable in this study (Table 1$)$.

Table 1

Constructs reliability values

\begin{tabular}{lcccccc}
\hline Constructs & \multicolumn{3}{c}{ Private Banks } & \multicolumn{3}{c}{ Public Banks } \\
\hline & $(\alpha)$ & CR & AVE & $(\alpha)$ & CR & AVE \\
\hline Empowerment & 0.890 & 0.870 & 0.561 & 0.770 & 0.720 & 0.543 \\
Professionalism & 0.820 & 0.770 & 0.522 & 0.780 & 0.710 & 0.511 \\
Training Methods & 0.930 & 0.880 & 0.641 & 0.720 & 0.700 & 0.587 \\
\hline
\end{tabular}

Next step is to confirm discriminant (external) validity of the model. Therefore, FornellLarcker test is considered in this study. "The Fornell-Larcker criterion based on the correlation among the exogenous variables while such values of the variables are compared with the square root of AVEs" (Hair Jr et al., 2016).

Table 2

Fornell-Larcker Criterion (Constructs validity values)

\begin{tabular}{lccc}
\hline \multicolumn{4}{c}{ Private Banks } \\
\hline Constructs & Empowerment & Professionalism & Training Methods \\
\hline Empowerment & 0.721 & 0.718 & \\
Professionalism & 0.677 & 0.622 & 0.712 \\
Training Methods & 0.706 & 0.710 & \\
\hline \multicolumn{4}{c}{ Public Banks } \\
\hline Empowerment & 0.714 \\
Professionalism & 0.623 & 0.614 & 0.705 \\
Training Methods & 0.702 & & \\
\hline
\end{tabular}

Above table confirmed that the correlation between all research variables is less than the square root averages (AVEs) that are highlighted in crosswise manner. Therefore, it is confirmed that the model satisfies discriminant (external) validity criterion. Moreover, Heterotrait-monotrait ratio of correlations (HTMT) is a new criteria to evaluate the 
discriminant validity (Hair Jr et al., 2016). The values of HTMT should be less than 1 . Therefore, this study found the all values of HTMT under 1 . The results can be seen in table 3. Since, reliability and validity has been confirmed, now the relationship between research variables are determined.

\begin{tabular}{lccc} 
Table 3 \\
Heterotrait-monotrait ratio of correlations (HTMT) \\
\hline \multicolumn{4}{c}{ Private Banks } \\
\hline Constructs & Empowerment & Professionalism & Training Methods \\
\hline Empowerment & 0.785 & 0.683 & \\
Professionalism & 0.737 & 0.647 & 0.593 \\
Training Methods & 0.721 & \multicolumn{4}{c}{ Public Banks } \\
\hline \multicolumn{4}{c}{} \\
\hline Empowerment & 0.764 & 0.629 & 0.505 \\
Professionalism & 0.752 & 0.631 & \\
Training Methods & 0.713 &
\end{tabular}

\section{Structural Model}

The second step of SEM is to assess the relationship between variables of interest by testing the earlier stated research hypotheses. Structural equation modeling (SEM) has three main components, namely, (a) path coefficient criteria, (b) coefficient of determination $\left(R^{2}\right)$ and (c) effect size $\left(f^{2}\right)$ respectively. "The criteria in path coefficient is assessed through considering t-value, which should be equal or greater than 1.96 at 0.05 significance level" (Imran, 2018). " $R^{2}$ shows the variability within the dependent variable caused by latent variables and rule of thumb is $R^{2}=0.75$ reflects substantial, 0.50 indicates moderate while 0.25 is weak variability" (Hair Jr et al., 2016). Lastly, Imran (2018) stated, "the effect size $\left(f^{2}\right)$ of up to 0.02 (small), 0.15 (moderate), and 0.35 (strong)".

Table 4

Structural Model results

\begin{tabular}{lcccccc}
\hline Hypothesis & $\beta$ & SD & T Value & Decision & $f^{2}$ & $R^{2}$ \\
\hline \multicolumn{7}{c}{ Private Banks } \\
\hline Training Methods - $>$ Empowerment & 0.385 & 0.088 & 4.375 & $0.000^{* *}$ & 0.351 & 0.755 \\
Training Methods - Professionalism & 0.465 & 0.065 & 7.153 & $0.000^{* *}$ & 0.385 & \\
Empowerment - $>$ Professionalism & 0.298 & 0.032 & 9.312 & $0.000^{* *}$ & 0.374 & \\
\hline \multicolumn{7}{c}{ Public Banks } \\
\hline Training Methods - $>$ Empowerment & 0.217 & 0.125 & 1.736 & $0.082 \mathrm{~ns}$ & 0.011 & 0.376 \\
Training Methods - $>$ Professionalism & 0.395 & 0.206 & 1.926 & $0.061 \mathrm{~ns}$ & 0.006 & \\
Empowerment $->$ Professionalism & 0.216 & 0.142 & 1.251 & $0.097 \mathrm{~ns}$ & 0.013 & \\
\hline Note: ${ }^{* * *} \mathrm{p}<0.1,{ }^{* *} \mathrm{p}<0.05, \mathrm{~ns}=$ non-significant $(\mathrm{p}>.05)$ (Two Tail) \\
\end{tabular}

Table 5

Path Coefficients in the Baseline Model

\begin{tabular}{lc}
\hline Structural Path & Path Coefficients \\
\hline Training Methods $\rightarrow$ Empowerment & $.760^{* *}$ \\
Training Methods $\rightarrow$ Professionalism & $.690^{* *}$ \\
Empowerment $\rightarrow$ Professionalism & $.620^{* *}$ \\
\hline Notes: ${ }^{*} p<05^{* *} \mathrm{p}<01^{* * *} \mathrm{p}<001$ &
\end{tabular}


In this study, R2 in private and public banks showed substantial regression, Private banks $\left(R^{2}=0.755\right)$, reflecting $75.5 \%$ variability in empowerment and professionalism is caused by modern training methods whereas in public banks $\left(R^{2}=0.376\right)$ showing that $37.6 \%$ variability caused by traditional methods in empowerment and professionalism. Thus, it confirms that modern methods of training have significant linkage with empowerment and professionalism in the private banks in comparison to traditional methods operating in public banks. Moreover, the employment status (permanent versus contractual) was found significant in contrast to other demographic variables, thus, it is considered as a control variable (Table 5).

Hypothesis 1 stated that modern methods of T\&D are more effective than the traditional methods of T\&D in improving the empowerment of permanent employees as compared to contractual employees in the banking sector of Pakistan. The statistical results confirmed a positive association in the private banks $(\alpha=0.385, \mathrm{p}<\alpha=0.000<0.05$; Table 4). On the other hand, results also revealed that traditional methods are non-significant in improving the empowerment of employees in the public banks $(\beta=0.217, \mathrm{p}>\alpha=0.082$ $>0.05$; Table 4). Hence, in the light of evidence, hypothesis 1 is retained.

Hypothesis 2 stated that Modern methods of T\&D are more effective than the traditional methods of T\&D in developing professionalism of permanent employees as compared to contractual employees in the banking sector of Pakistan. Statistical results confirmed positive linkage in private banks $(\beta=0.465, \mathrm{p}<\alpha=0.000<0.05$; Table 4) while non-significant impact is evident in public banks $(\beta=0.395, \mathrm{p}>\alpha=0.061>0.05$; Table 4). Hence, we fail to reject hypothesis 2 .

Lastly, hypothesis 3 stated that empowerment enhances the professionalism among permanent employees in comparison to contractual employees in the banking sector of Pakistan. Statistical results confirmed that empowerment has positive role in enhancing the professionalism among permanent employees in contrast to contractual employees in Private banks ( $\beta=0.298, \mathrm{p}<\alpha=0.000<0.05$; Table 4) than public banks, reflecting nonsignificant association ( $\beta=0.216, \mathrm{p}>\alpha=0.097>0.05$; Table 4 ; CI values between 0.62 to 0.6 , Table 5). Thus, hypothesis 3 is supported.

\section{Discussion}

Present study's results indicated that modern methods in comparison to traditional methods are more effective in improving the empowerment and professionalism of the employees. The modern methods which are commonly used in the private banks have the tendency to positively affect the permanent employees by developing empowerment among them. There is a positive association between empowerment and modern training method. Therefore, this study supports the earlier empirical studies (Faridi \& Baloch, 2018; Nawaz et al., 2014). Moreover, this study also found that professionalism is significant and positively affected by the modern methods of training. Professionalism is higher among the employees having adequate training, which reflects that this study supports the notion of Nawaz et al. (2014). It also indicates that different methods of training and development are constructive in improving the employees working efficiency, professional attitude, and engagement at work, reflecting that there is higher a professionalism, 
therefore, this study supports the arguments of Faridi and Baloch (2018); Kulkarni (2013) in this regard. Since empowerment and professionalism show the development of employees' psychological and intellectual capital, thus, this study is aligned with the work of Kulkarni (2013). However, the present study could not find the linkage of professionalism and empowerment interlinked with creative and innovative behaviour of employees in the organizational settings. Hence, this study partially differs with the work of Karatepe (2012) in this regard.

Using the lens of Social exchange theory, it could be argued that private banks take care of its employees by providing them necessary training through advanced and latest technology, therefore, in return employees show higher commitment and take initiative to do tasks by their own. Hence, this study partially supports the notion of Andrew and Sofian (2012) and Cropanzano and Mitchell (2005). Additionally, the T\&D is found to be a significant HR practice to develop required knowledge, skills, abilities, and capabilities. As a result, this study supports previous studies (Faizan \& Zehra, 2016; Faridi \& Baloch, 2018; Kulkarni, 2013). Moreover, this study confirmed that behavioural engagement leads to proper execution of tasks, higher sense of responsibility, reflecting higher level of empowerment and professionalism. Thus, the study is aligned with the work of Nawaz et al. (2014). Since, in the public banks there was an evidence of lower productivity and traces of higher disengagement. Hence to some extent the work of Saks (2006) is confirmed.

Karatepe (2012)'s argument supported that empowered employees are more dedicated and reflect higher professionalism as this study found that empowerment leads to higher demonstration of professionalism. However, it differs from the work of Nawaz et al. (2014) that empowered employees show higher creative skills at work.

Previously, the studies of Faridi et al. (2017); Rehman (2012) stated that the HR practices are differing in the developed and emerging economies. However, this study found that although traditional methods are less effective but modern methods are significantly effective in the emerging economy. Thus, this study partially differs from their work. Interestingly, the earlier work of Zehra (2016) explained T\&D as a barometer for measuring employees and bank's performance, which indirectly is supported by present findings as those employees receive proper training demonstrated by higher commitment, professionalism and empowerment. As a result, those organizations are found to be doing better than those having no such appropriate training sessions. The retention rate of employees in private banks remain stable, which indicates that proper training develops positive psychology. Thus, the work of Batool and Batool (2012); Caldwell (2003); Hales (2005) are supported to larger extent.

Thus, in the light of evidence, it is confirmed that modern training methods is more effective than the traditional methods because they develop higher professionalism and empowerment among permanent employees in the private banks. Moreover, the study theorizes that empowerment leads to create higher professionalism in the service sector.

The conclusion is drawn that private banks are performing better than the public banks due to the use of modern methods of training and development. Furthermore, the permanent employees benefit more from the modern methods of T\&D at private banks. In contrast to the traditional methods, modern methods are more effective in developing the professionalism and empowerment by engaging them at workplace using latest tech- 
nologies. Nevertheless, the empowerment and professionalism are not linked with the innovative and creative behaviour but develops the positive attitude towards assigned task to be completed in adequate manner, following the directions from the top management. It is also found that empowered employees demonstrate greater professionalism, which is the automatic result of the active participation in the modern training and development programs.

\section{Limitations and Suggestions}

Despite using adequate measures to ensure that this study is carried out in best manner, there are certain limitations attached with this study. The data is gathered from banks in Pakistan based on the convenience and purposive sampling, therefore it does only convey the perspective of the selected cases rather than offering holistic one. In addition to that, it does offer national perspective but lacks the global perspective because the results are confined only to one specific country. Hence, the findings can only be generalized to the selective banks of one country. Ideally, the researchers in future shall consider comparative aspect by comparing the banking sectors of other developed and emerging economies in order to have broader generalization. It would offer global perspective, which would delimit present study. Moreover, although, more than one sampling technique was used to ensure there is no over reliance on one technique, but this approach has its own limitation. Purposely banks with specific training methods were targeted while only those participants were included on convenience. The merit is that these techniques served the research objectives by investigating in-depth rather than width, yet area cluster sampling would have offered a more holistic sample and fair representation of banking sector. Hence, in future, researcher shall consider area cluster sampling technique to have true and fair representation from all parts of the country, which would reflect fair national perspective. This study focused on quantitative methods in order to gain 'factual truth' while little is known about 'useful truth' (qualitative perspective). In future, researchers will consider the qualitative aspect in order to explore the research phenomenon in depth.

\section{Implications}

Findings could be used to improve the training methods in the banking sector of Pakistan. It would improve the working efficiency and performance of the banks as well as of employees. The findings imply that permanent employees demonstrate higher professionalism due to the job security whereas contractual employees lag them. Similarly, the findings imply that empowerment is higher among employees who have permanent job status. It also implies that modern methods are more effective in the transformation of resources in adequate manner. In order to be more productive, organizations should focus on the use of latest technologies. 


\section{References}

Aho, I. (2013). Value-added business models: Linking professionalism and delivery of sustainability. Building Research \& Information, 41(1), 110-114.

Ali, Z., Bashir, M., \& Mehreen, A. (2019). Managing organizational effectiveness through talent management and career development: The mediating role of employee engagement. Journal of Management Sciences, 6(1), 62-78.

Andrew, O. C., \& Sofian, S. (2012). Individual factors and work outcomes of employee engagement. Procedia-Social and Behavioral Sciences, 40, 498-508.

Baldoni, J. (2005). Great motivation secrets of great leaders. New York: McGraw-Hill.

Batool, A., \& Batool, B. (2012). Effects of employees training on the organizational competitive advantage: Empirical study of private sector of Islamabad, Pakistan. Far East Journal of Psychology and Business, 6(5), 59-72.

Bloom, N., \& Van Reenen, J. (2007). Measuring and explaining management practices across firms and countries. The Quarterly Journal of Economics, 122(4), 1351-1408.

Boshoff, C., \& Allen, J. (2000). The influence of selected antecedents on frontline staff's perceptions of service recovery performance. International Journal of Service Industry Management, 11(1), 63-90.

Brown, E. (2013). Vulnerability and the basis of business ethics: From fiduciary duties to professionalism. Journal of Business Ethics, 113(3), 489-504.

Brown, K. W., \& Ryan, R. M. (2003). The benefits of being present: Mindfulness and its role in psychological well-being. Journal of Personality and Social Psychology, 84(4), 822-848.

Caldwell, R. (2003). The changing roles of personnel managers: Old ambiguities, new uncertainties. Journal of Management Studies, 40(4), 983-1004.

Chughtai, M. W., \& Nadeem, Z. A. (2016). Exploring the effects of training and development practices on organization performance: A case study of Pakistan telecommunication authority. Asian Journal of Social Sciences and Management Studies, 3(1), 47-55.

Cropanzano, R., \& Mitchell, M. S. (2005). Social exchange theory: An interdisciplinary review. Journal of Management, 31(6), 874-900.

De Munnik, D., Dupuis, D., \& Illing, M. (2009). Computing the accuracy of complex nonrandom sampling methods: The case of the bank of Canada's business outlook survey (Tech. Rep.). Bank of Canada Working Paper.

Dinger, M., Thatcher, J. B., Treadway, D., Stepina, L., \& Breland, J. (2015). Does professionalism matter in the it workforce? An empirical examination of IT professionals. Journal of the Association for Information Systems, 16(4), 281-313.

Faizan, R., Haque, A., Cockrill, A., \& Aston, J. (2019). Females at strategic level affecting logistics firms' competitiveness: Qualitative comparative analysis of contrasting gender in Pakistan and Canada. Forum Scientiae Oeconomia, 7(1), 57-71.

Faizan, R., \& Zehra, N. (2016). Quality work-life as predictor to organisational commitment under contrasting leadership styles: IT Responses from Pakistans private software houses. Global Journal of Management And Business Research, 16(6), 9-23. 
Faridi, A., \& Baloch, A. (2018). The moderating role of modern training and development methods in private banks and work performance: Evidence from contractual employees working in Pakistan banking sector. Business $\mathcal{E}$ Management Studies: An International Journal, 6(3), 204-215.

Faridi, A., Baloch, A., \& Wajidi, A. (2017). Job satisfaction and organizational commitment under traditional and modern T\&D program: Evidence from public banking sector of Pakistan. International Journal of Applied Business and Management Studies, 2(1), 9-16.

Ferguson, R. P. (2014). Professionalism: hard to measure but you know it when you see it. United Kingdom: Taylor \& Francis.

Gusdorf, M. L. (2009). Training design, development and implementation. Alexandria, VA: SHRM Academic Initiatives.

Hair Jr, J. F., Hult, G. T. M., Ringle, C., \& Sarstedt, M. (2016). A primer on partial least squares structural equation modeling (PLS-SEM). Sage publications.

Hales, C. (2005). Rooted in supervision, branching into management: Continuity and change in the role of first-line manager. Journal of Management Studies, 42(3), 471506.

Haque, A. U., \& Oino, I. (2019). Managerial challenges for software houses related to work, worker and workplace: Stress reduction and sustenance of human capital. Polish Journal of Management Studies, 19(1), 170-189.

Hayes, B. E. (1994). How to measure empowerment. Quality Progress, 27, 41-41.

Imran, M. (2018). Influence of industry 4.0 on the production and service sectors in Pakistan: Evidence from textile and logistics industries. Social Sciences, 7(12). doi: 10.3390 / socsci7120246

Jaffery, H., \& Farooq, H. (2015). The impact of structural empowerment on organizational citizenship behavior-organization and job performance: A mediating role of burnout. Journal of Management Sciences, 2(2), 273-288.

Jamal, S. (2011). Statistics problems and practice Edition 2013 for B.Com. Karachi: Ahmed Academy.

Karatepe, O. M. (2012). Perceived organizational support, career satisfaction, and performance outcomes: A study of hotel employees in cameroon. International Journal of Contemporary Hospitality Management, 24(5), 735-752.

Kot, S., Haque, A. U., \& Kozlovski, E. (2019). Strategic SCM's mediating effect on the sustainable operations: Multinational perspective. Organizacija, 52(3), 219-235.

Kulkarni, P. P. (2013). A literature review on training \& development and quality of work life. Researchers World, 4(2), 136-143.

LeBlanc, D. C. (2004). Statistics: concepts and applications for science. UK, Sudbury: Jones and Bartlett Publisher.

Levy, J., Wubbels, T., Den Brok, P., \& Brekelmans, M. (2003). Students' perceptions of interpersonal aspects of the learning environment. Learning Environments Research, $6(1), 5-36$.

Louangrath, P. (2013). Alpha and beta tests for Type I and Type II inferential errors determination in hypothesis testing. Retrieved from https://ssrn.com/abstract= 2332756.DOI:10.2139/ssrn.2332756 (Accessedon:08-10-2019) 
McClelland, S. D. (2002). A training needs assessment for the united way of Dunn County Wisconsin. Retrieved from Retrievedfrom: http://www. uwstout.edu/lib/ thesis/2002/2002mcclellands.pdf. (Accessedon:08-09-2018)

McNamara, C. (2008). Employee training and development: Reasons and benefits. Retrieved from Retrievedfrom:http://www. managementhelp.org/index .html. (Accessedon:08-09-2018)

Mukwakungu, S. C., Mankazana, S., \& Mbohwa, C. (2018). The impact of employee empowerment on organizational performance in a flavors and fragrance manufacturing company in South Africa. Retrieved from Retrievedfrom:https://www.researchgate.net/publication/ 326977251_The_Impact_of_Employee_Empowerment_on_Organizational _Performance_in_a_Flavours_and_Fragrance_Manufacturing_Company -in_South_Africa (Accessedon:08-10-2019)

Nawaz, M. S., Hassan, M., Hassan, S., Shaukat, S., \& Asadullah, M. A. (2014). Impact of employee training and empowerment on employee creativity through employee engagement: Empirical evidence from the manufacturing sector of Pakistan. MiddleEast Journal of Scientific Research, 19(4), 593-601.

Noe, R. A., \& Peacock, M. (2008). Employee training and development. New York: McGrawHill, Inc.

Rehman, M. S. (2012). Employee turnover and retention strategies: An empirical study of public sector organizations of Pakistan. Global Journal of Management and Business Research, 12(1), 1-8.

Rowland, A. W. (2016). What is professionalism? The validation of a comprehensive model of professionalism. Retrieved from http: //digitalcommons.wku.edu/ theses/1741 (Accessedon:08-10-2019)

Rumsey, D. J. (2002). Statistical literacy as a goal for introductory statistics courses. Journal of Statistics Education, 10(3). Retrieved from http://www.amstat.org/ publications/jse/v10n3/rumsey2.html (Accessedon:08-10-2019)

Sekaran, U., \& Bougie, R. (2016). Research methods for business: A skill building approach. West Sussex, UK: John Wiley \& Sons Ltd.

Shafiq, S., \& Hamza, S. M. (2017). The effect of training and development on employee performance in private company Malaysia. International Journal of Education, Learning and Training, 2(2), 42-56.

Stone, D. L., Stone-Romero, E. F., \& Lukaszewski, K. (2006). Factors affecting the acceptance and effectiveness of electronic human resource systems. Human Resource Management Review, 16(2), 229-244.

Urbański, M., Haque, A. U., \& Oino, I. (2019). The moderating role of risk management in project planning and project success: Evidence from construction businesses of Pakistan and the UK. Engineering Management in Production and Services, 11(1), 2335.

Wijnhoven, F., Ehrenhard, M., \& Kuhn, J. (2015). Open government objectives and participation motivations. Government Information Quarterly, 32(1), 30-42.

Zehra, N. (2016). Training \& development barometer for effective transformation of organizational commitment and overall performance in banking sectors of KPK, Pak- 
istan: Qualitative study of workforce of bank of Khyber. International Journal of Academic Research in Business and Social Sciences, 6(6).

Zehra, N., \& Faizan, R. (2017). The impact of occupational stress on employees at project based organizations (PBOs) in Pakistan. International Journal of Applied Business and Management Studies, 2(1), 1-9. 